\title{
Effect of barium iron tantalate incorporation on mechanical, electrical, and magnetocapacitance properties of modified bismuth sodium potassium titanate ceramics
}

\author{
Pharatree Jaita $^{\mathrm{a}, \mathrm{b}}$, Ratabongkot Sanjoom ${ }^{\mathrm{c}}$, Narumon Lertcumfu ${ }^{\mathrm{d}}$, Pruchya Malasri ${ }^{\mathrm{a}}$, \\ Gobwute Rujijangul ${ }^{\mathrm{a}, \mathrm{b}, \mathrm{e}, \mathrm{f}, *}$, Tawee Tunkasiri ${ }^{\mathrm{a}, \mathrm{e}}$ \\ a Department of Physics and Materials Science, Faculty of Science, Chiang Mai University, Chiang Mai \\ 50200 Thailand \\ b Science and Technology Research Institute, Chiang Mai University, Chiang Mai 50200 Thailand \\ c Department of Applied Science and Biotechnology, Faculty of Agro-Industrial Technology, Rajamangala \\ University of Technology Tawan-ok, Chantaburi Campus, Chantaburi 22210 Thailand \\ d Department of Gemological Sciences, Faculty of Gemological Sciences and Applied Arts, Rambhai Barni \\ Rajabhat University, Chanthaburi 22000 Thailand \\ e Center of Excellence in Materials Science and Technology, Materials Science Research Center, Faculty of \\ Science, Chiang Mai University, Chiang Mai 50200 Thailand \\ f Research Center in Physics and Astronomy, Faculty of Science, Chiang Mai University, Chiang Mai 50200 \\ Thailand
}

*Corresponding author, e-mail: rujijanagul@yahoo.com

Received 16 Oct 2019

Accepted 27 Dec 2019

\begin{abstract}
In this research, the $(1-x)$ (BNKT-BST)- $x$ BFTa ceramics were fabricated via a solid-state mixed oxide method and sintered at the temperature of $1125^{\circ} \mathrm{C}$ for $2 \mathrm{~h}$ dwell time in order to obtain dense ceramics. The XRD and Raman data revealed the coexisting rhombohedral and tetragonal phases for all samples. The density increased with increasing the additive content, which resulted in the improvements of mechanical and dielectric properties. The maximum dielectric $\left(\varepsilon_{r}=1799\right)$ and mechanical properties $\left(H_{\mathrm{V}}=6.30 \mathrm{GPa}, H_{\mathrm{K}}=5.30 \mathrm{GPa}, E=97 \mathrm{GPa}\right.$ and $K_{\mathrm{IC}}=1.95 \mathrm{MPa}^{1 / 2}$ ) were observed. The leakage current density $(J)$ increased with increasing amount of the additive at high electric fields of $30 \mathrm{kV} / \mathrm{cm}$ while the resistivity $(\rho)$ was also found to decrease with the additive. The magnetocapacitance $(-M C \%)$ value also increased with increasing of the additive. The obtained results suggested that the additive not only enhanced the mechanical but also improved electrical properties of the studied samples.
\end{abstract}

KEYWORDS: lead-free ceramic, bismuth sodium potassium titanate, magnetocapacitance, leakage current density

\section{INTRODUCTION}

Although lead-based materials such as lead zirconate titanate (PZT) show good electrical properties, these materials are toxic, volatile, and harmful to human health and the environment (PZT contains $60 \mathrm{wt} \%$ of $\mathrm{PbO})[1,2]$. Therefore, leadfree materials have been developed, and intensively studied due to the environmental concern [1-3]. Among the materials, bismuth sodium titanate or $\left(\mathrm{Bi}_{0.5} \mathrm{Na}_{0.5}\right) \mathrm{TiO}_{3}$ (BNT) ceramic is an interesting lead-free piezoelectric material due to the fact that it presents good electrical properties such as good ferroelectric and piezoelectric properties [2]. Much attention has thus been focused on BNT-based ma- terials, i.e., BNT-BT, BNT-BZ, and BNT-KNN [2]. Many modified BNT materials have been studied due to some problems from the pure BNT such as the large coercive field $\left(E_{\mathrm{c}} \sim 73 \mathrm{kV} / \mathrm{cm}\right)$ and high electrical conductivity which is not suitable for practical applications [4]. Furthermore, the modified BNT materials present many interesting properties. Many authors have reported that bismuth sodium potassium titanate or $\mathrm{Bi}_{0.5}\left(\mathrm{Na}_{1-x} \mathrm{~K}_{x}\right)_{0.5} \mathrm{TiO}_{3}$ (BNKT) ceramics, a modified BNT, possess many desire properties as compared to the pure BNT ceramic [4-7]. Jaita et al [6] reported that BNKT modified by barium strontium titanate $\left(\left(\mathrm{Ba}_{0.70} \mathrm{Sr}_{0.30}\right) \mathrm{TiO}_{3}\right)$ or BNKT-BST showed many good electrical properties 
such as high electric field-induced strain response. Many modified BNKT-BST ceramics have also been developed, and these materials showed many high electrical properties. For example, BNKT-BST doped with La ceramics showed an improvement of electric field-induced strain response [8], BNKT-BST doped with $\mathrm{Fe}_{2} \mathrm{O}_{3}$ nanoparticles promoted a diffuse phase transition and reduced resistivity with high electric field-induced strain [6], and BNKT-BST doped with $\mathrm{Nb}$ presented high normalized strain coefficient $\left(d_{33}^{*}\right)$ [7]. Therefore, further modified BNKTBST materials are expected to be good for future development of electronic materials.

Barium iron tantalate, $\mathrm{Ba}\left(\mathrm{Fe}_{0.5} \mathrm{Ta}_{0.5}\right) \mathrm{O}_{3}$ or $\mathrm{BFTa}$ is a high dielectric material which presents the dielectric constant varying from $10^{3}-10^{5}$ for a wide temperature range with frequency dependence and no ferroelectric property $[9,10]$. At room temperature (RT), BFTa ceramic has a space group Pm3m (211) [10] and the lattice parameter of $4.056 \AA$ [11]. Materials containing BFTa present many advantage properties as compared with those of a pure BFTa such as BFTa-Ba $\left(\mathrm{Zn}_{1 / 3} \mathrm{Ta}_{2 / 3}\right) \mathrm{O}_{3}$ which showed higher dielectric constants with lower loss tangents [12], $\mathrm{BFTa}-\mathrm{BiFeO}_{3}$ which presented an improvement in magnetic properties [9] and $\mathrm{K}_{0.5} \mathrm{Na}_{0.5} \mathrm{NbO}_{3}$-BFTa which presented an improvement in the ferroelectric properties [13]. Phase transition temperature of $\mathrm{BaTiO}_{3}$-BFTa system can be tuned by BFTa additive [14]. It is expected that properties of other materials which contain BFTa may show many interesting properties.

For some applications, i.e., at high stress or high electric field, the mechanical properties are needed. However, most works for the modified BNKT-BST ceramics are concentrated in only their electrical properties. Furthermore, the mechanical properties of the modified BNKT-BST ceramics have not been widely investigated. In this work, the mechanical properties of BNKT-BST ceramics modified by BFTa were thus investigated. Electrical properties of these ceramics were also studied. It was found that BFTa additive could improve both mechanical and electrical properties of the studied ceramics.

\section{MATERIALS AND METHODS}

The conventional mixed oxide technique was applied to synthesize the mixed powder of $(1-x)\left[\mathrm{Bi}_{0.5}\left(\mathrm{Na}_{0.80} \mathrm{~K}_{0.20}\right)_{0.5} \mathrm{TiO}_{3}\right.$ $\left.0.03\left(\mathrm{Ba}_{0.70} \mathrm{Sr}_{0.03}\right) \mathrm{TiO}_{3}\right]-x \mathrm{Ba}\left(\mathrm{Fe}_{0.5} \mathrm{Ta}_{0.5}\right) \mathrm{O}_{3}$, referred to as $(1-x)$ (BNKT-BST)- $x$ BFTa. Reagent-grade powders of $\mathrm{Bi}_{2} \mathrm{O}_{3}, \mathrm{Na}_{2} \mathrm{CO}_{3}, \mathrm{TiO}_{2}, \mathrm{~K}_{2} \mathrm{CO}_{3}, \mathrm{BaCO}_{3}$, $\mathrm{SrCO}_{3}, \mathrm{Fe}_{2} \mathrm{O}_{3}$, and $\mathrm{Ta}_{2} \mathrm{O}_{5}$ were used as the starting
Table 1 The mix proportion (by mol\%) of each condition of the $(1-x)$ (BNKT-BST)- $x$ BFTa ceramics.

\begin{tabular}{lccc}
\hline$x$ & BNKT-BST $(\mathrm{g})$ & BFTa $(\mathrm{g})$ & No. of sample \\
\hline 0 & 100 & 0 & 5 \\
0.01 & 98.5844 & 1.4156 & 5 \\
0.02 & 97.1806 & 2.8194 & 5 \\
0.03 & 95.7885 & 4.2115 & 5 \\
\hline
\end{tabular}

raw materials. All carbonate powders were first dried at $120^{\circ} \mathrm{C}$ for $24 \mathrm{~h}$ in order to remove any moisture. The raw materials of BNKT-BST and BFTa were separately stoichiometrically weighed and mixed by ball milling in $99.9 \%$ ethanol for $24 \mathrm{~h}$ and the slurry was dried using an oven. Dried BNKT-BST and BFTa powders were separately calcined in a closed $\mathrm{Al}_{2} \mathrm{O}_{3}$ crucible at $900^{\circ} \mathrm{C} / 2 \mathrm{~h}$ and $1200^{\circ} \mathrm{C} / 4 \mathrm{~h}$, respectively. Both calcined powders were then weighed and mixed in order to produce an appropriate stoichiometry for the compositions $(1-x)$ (BNKT-BST)- $x$ BFTa with $x=$ $0,0.01,0.02$, and $0.03 \mathrm{~mol}$ fraction. The mix proportion (by mol\%) of each condition of the $(1-x)$ (BNKT-BST)-xBFTa ceramics and number of sample were showed in Table 1. After drying and sieving, the powders were granulated by adding a few drops of $4 \mathrm{wt} \%$ polyvinyl alcohol (PVA) as a binder and then pressed into disks with $10 \mathrm{~mm}$ in diameter and about $1.3 \mathrm{~mm}$ in thickness. Finally, the pellets were placed in a sealed alumina crucible and covered with a powder of the same composition before being sintered at $1125^{\circ} \mathrm{C}$ for $2 \mathrm{~h}$ dwell time with a heating/cooling rate of $5^{\circ} \mathrm{C} / \mathrm{min}$.

An X-ray diffractometer (XRD-Phillip, X-pert) was used to identify phase of sintered ceramics. Bulk density of all ceramics was determined using the Archimedes' method. Raman spectra were obtained by Raman spectroscopy for all ceramics. For the measurement of mechanical properties, the samples were polished to a mirror finish. The wellpolished ceramics were then subjected to microhardness tester for both Knoop $\left(H_{\mathrm{K}}\right)$ and Vickers hardness $\left(H_{\mathrm{V}}\right)$ determination. The indentation load used was $1000 \mathrm{~N}$ which was applied for $15 \mathrm{~s}$ holding time. Young modulus $(E)$ was determined following the method described by Marshall et al [15]. Fracture toughness $\left(K_{\mathrm{IC}}\right)$ was also calculated from the cracks' length propagated from 4 corners of the indentation impression following the method described by Anstis et al [16]. For the electrical measurements, the samples were polished to produce very smooth and parallel surfaces, and silver 
Table 2 Physical, microstructure and mechanical properties of the $(1-x)$ (BNKT-BST)- $x$ BFTa ceramics.

\begin{tabular}{lcccccc}
\hline$x$ & $\begin{array}{c}\text { Density } \\
\left(\mathrm{g} / \mathrm{cm}^{3}\right)\end{array}$ & $\begin{array}{c}\text { Grain size } \\
(\mu \mathrm{m})\end{array}$ & $\begin{array}{c}H_{\mathrm{V}} \\
(\mathrm{GPa})\end{array}$ & $\begin{array}{c}H_{\mathrm{K}} \\
(\mathrm{GPa})\end{array}$ & $\begin{array}{c}E \\
(\mathrm{GPa})\end{array}$ & $\begin{array}{c}K_{\mathrm{IC}} \\
\left(\mathrm{MPa} . \mathrm{m}^{1 / 2}\right)\end{array}$ \\
\hline 0 & 5.80 & 0.59 & 5.30 & 4.10 & 62 & 1.35 \\
0.01 & 5.83 & 0.58 & 4.85 & 4.85 & 80 & 1.58 \\
0.02 & 5.85 & 0.57 & 5.00 & 5.00 & 82 & 1.86 \\
0.03 & 5.86 & 0.55 & 5.30 & 5.30 & 97 & 1.95 \\
\hline
\end{tabular}

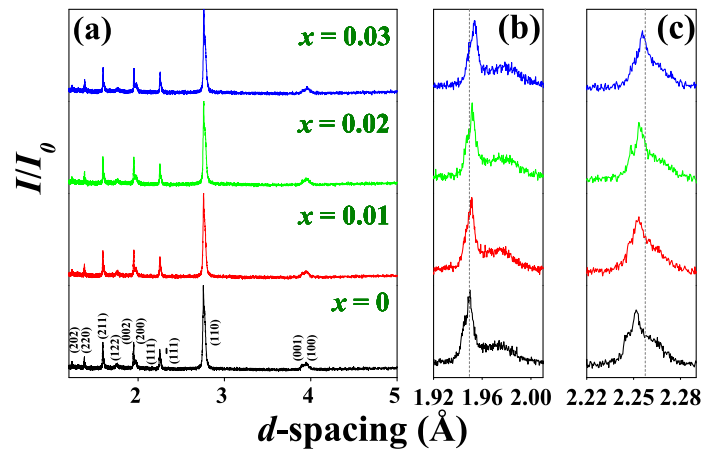

Fig. 1 X-ray diffraction patterns (XRD) of the $(1-x)$ (BNKT-BST) $x$ BFTa ceramics: (a) $d=1.2-5.0 \AA$, (b) $d=1.90-2.01 \AA$, and (c) $d=2.22-2.29 \AA$.

paste was coated on both sides of the samples and fired at $700^{\circ} \mathrm{C}$ for $30 \mathrm{~min}$. Dielectric properties were carried out using 4284A LCR-meter. Leakage current density versus applied electric field $(J-E)$ curve was carried out at electric field of $30 \mathrm{kV} / \mathrm{m}$. The resistivity $(\rho)$ and the magnetocapacitance ($M C \%)$ were also calculated.

\section{RESULTS AND DISCUSSION}

Green pellets of all compositions were sintered at the optimum temperature of $1125^{\circ} \mathrm{C}$ for $2 \mathrm{~h}$. High bulk densities of $5.80-5.86 \mathrm{~g} / \mathrm{cm}^{3}$ were achieved (Table 2). Based on the density values, it was clearly found that the addition of BFTa into BNKT-BST ceramic caused an increase in samples' density value. This is probably because BFT ceramic has the higher density value $\left(7.32-7.40 \mathrm{~g} / \mathrm{cm}^{3}\right)[9,12]$ when compared to that of BNKT-BST $\left(5.80 \mathrm{~g} / \mathrm{cm}^{3}\right)$ [6]. Thus, the increasing of density value was observed in the studied system.

X-ray diffraction data for all ceramics are shown in Fig. 1(a). It can be seen that all compositions possess a single perovskite phase without secondary phases or impurity peaks within the limit of the XRD machine. The XRD data also revealed the coexisting rhombohedral and tetragonal phases throughout the entire compositional range [17] as evidenced by a slight splitting of $(111)_{R} /(1 \overline{1} 1)_{R}$ rhombohedral

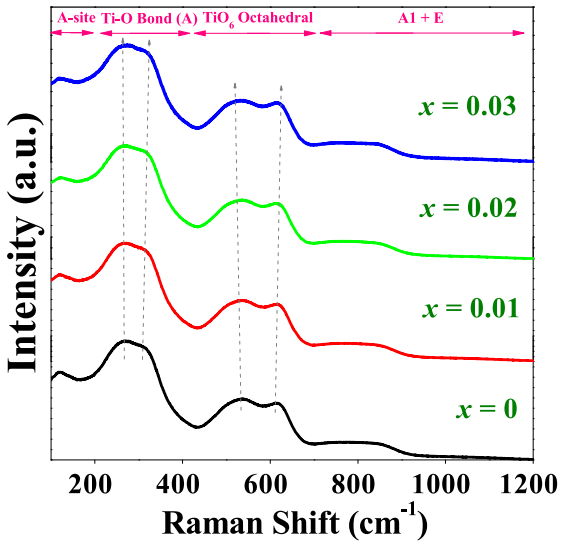

Fig. 2 Raman spectra of the $(1-x)$ (BNKT-BST)- $x$ BFTa ceramics measured at room temperature.

peak at $d=2.22-2.28 \AA$ and $(002)_{\mathrm{T}} /(200)_{\mathrm{T}}$ tetragonal peak $d=1.92-2.00 \AA$. For detailed analysis, the XRD patterns for selected narrow angular ranges of $d=1.90-2.01 \AA$ and $d=2.22-2.29 \AA$ are presented in Fig. 1(b) and (c), respectively. With an increasing BFTa content, the XRD peaks gradually shift to higher $\mathrm{d}$-spacing. This can be caused by the differences in the ionic radii between $\mathrm{Na}^{+}, \mathrm{Bi}^{3+}, \mathrm{K}^{+}$, $\mathrm{Sr}^{2+}$, and $\mathrm{Ba}^{2+}$ at the A-site and $\mathrm{Ti}^{4+}, \mathrm{Fe}^{3+}$, and $\mathrm{Ta}^{5+}$ at the $\mathrm{B}$-site which is a result of structural distortion.

To study the effect of BFTa addition on the phase formation in more details, Raman scattering technique was employed. Raman spectra of the (BNKT-BST)- $x$ BFTa ceramics at RT are displayed in Fig. 2. The obtained data showed that there were 4 main regions in the spectrum, and this information agrees with many previous reports [18-20]. The 4 main regions in the Raman data are as follows: (1) the observed vibrational mode at $\sim 135 \mathrm{~cm}^{-1}$ is linked with the vibrations of A-site cations in the perovskite structure, influenced by A-site doping; (2) the $260 \mathrm{~cm}^{-1}$ mode is related to Ti-O vibrations. Furthermore, this mode becomes broader and starts splitting into two bands with increasing the additive content, and this may be due to the co-occupancy of different cations (Ti/Ta, Fe) with different sizes at the B-site that results in the distortion of the unit cell [18]; (3) the $450-700 \mathrm{~cm}^{-1}$ region hosts modes that correspond to the vibration of the $\mathrm{TiO}_{6}$ octahedra. In this region, there is an overlapping band which was slightly separated into two distinct bands for the samples containing higher amount of additive, which demonstrated particular phonon behavior in the structural evolution and a phase mixture; and (4) the high-frequency region above 


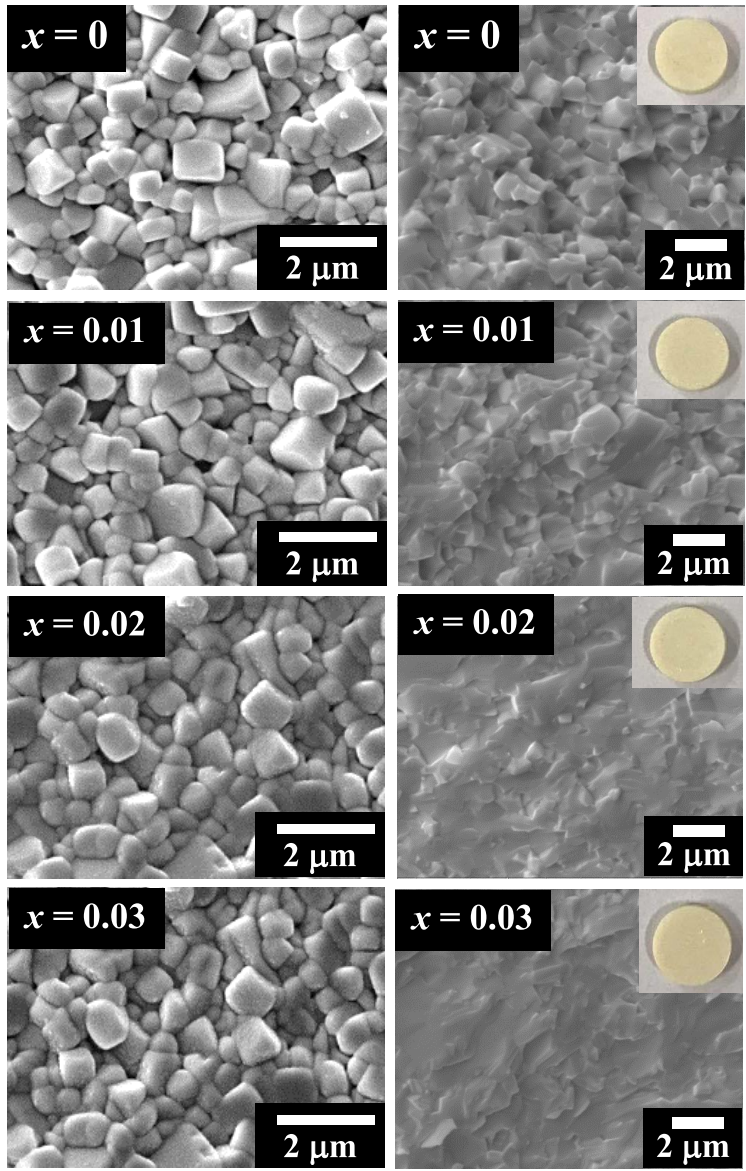

Fig. 3 SEM micrographs of the $(1-x)$ (BNKT-BST)- $x$ BFTa ceramics: (left) as-sintered surface mode and (right) fracture surface mode (products after sintering process).

$700 \mathrm{~cm}^{-1}$ feature modes can correspond to $A_{1}$ (longitudinal optical) and $\mathrm{E}$ (longitudinal optical) overlapping band $[19,20]$, respectively. The Raman scattering and the XRD data indicated that the additive significantly influences the host BNKT-BST perovskite.

Fig. 3 displays SEM micrographs of as-sintered surface and fracture surface of the ceramics (inset: products after sintering process). The average grain size values are also summarized in Table 2 . From the as-sintered surface images (left), microstructure and granular morphology are considerably welldeveloped in all samples. The unmodified sample had an average grain size of $0.59 \mu \mathrm{m}$. After adding the additive, the average grain size slightly decreased to $0.55-0.58 \mu \mathrm{m}$. The reduction in grain size may be mainly attributed to grain growth inhibition as a result from solute drag effect [21-23]. Thus, the incorporation of BFTa can restrain grain
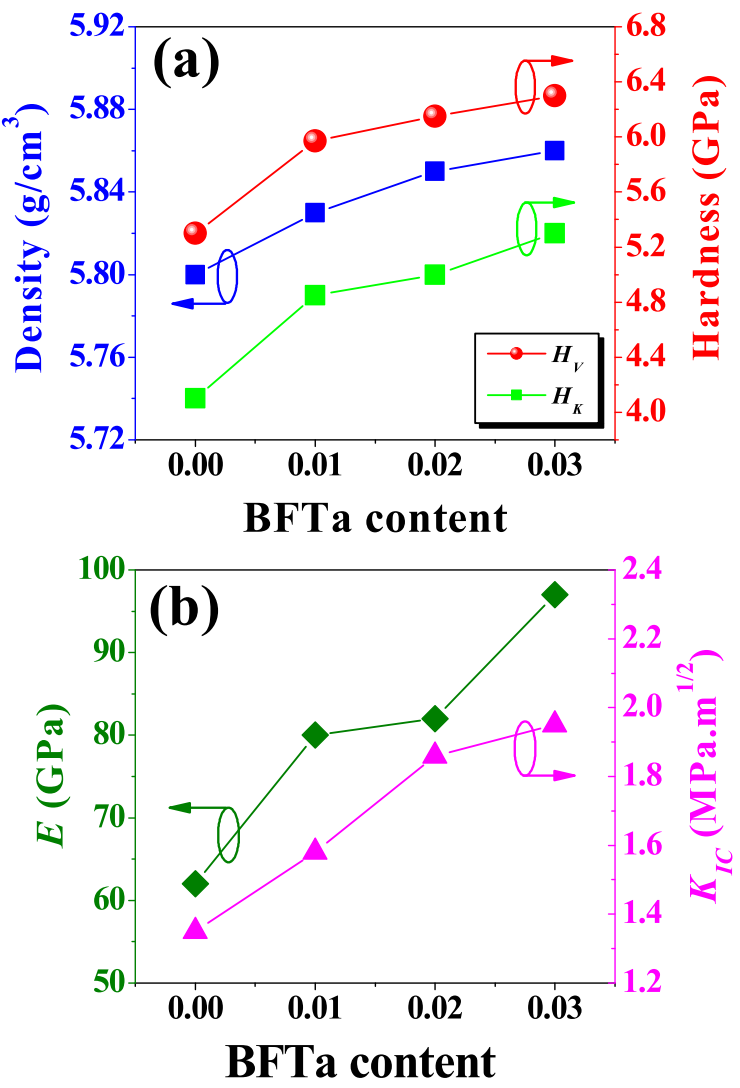

Fig. 4 (a) Plots of density, $H_{\mathrm{V}}$ and $H_{\mathrm{K}}$, (b) $E$ and $K_{\mathrm{IC}}$ as a function of the BFTa content of the ceramics.

growth in the BNKT-BST ceramics. Normally, the growth mechanism can occur by the grain boundary motion due to a reduction of the total grain boundary surface energy. Furthermore, the thermal energy can lead to an increase in the diffusion rate and consequently intensify the formation of necks between grains. Thus, the reason for the decrease of grain size can be explained based on the difference of ionic radii between host ion $\left(\mathrm{Ti}^{4+}\right)$ and doped ions $\left(\mathrm{Fe}^{3+}\right.$ and $\left.\mathrm{Ta}^{5+}\right)$. Since the ionic radius of $\mathrm{Fe}^{3+}$ $(0.78 \AA)$ and $\mathrm{Ta}^{5+}(0.74 \AA)$ are larger than that of $\mathrm{Ti}^{4+}(0.605 \AA)$, higher Fe and Ta concentration doping can result in less mobility of the ions and cause inhibited grain growth [22]. For fractured surface mode (right), the unmodified sample exhibited mainly intergranular fracture mode which indicated its relatively weak grain boundaries. The additive caused fracture behavior to switch from intergranular to transgranular mode, suggesting an increase in grain bountion dary strength [23].

Mechanical properties of the ceramics in terms of Vickers hardness $\left(H_{\mathrm{V}}\right)$, Knoop hardness $\left(H_{\mathrm{K}}\right)$, 
elastic modulus $(E)$, and fracture toughness $\left(K_{\mathrm{IC}}\right)$ were determined. The $H_{\mathrm{V}}$ and $H_{\mathrm{K}}$ of these ceramics were determined with a Leco Hardness Tester. Indentation was performed with a Vickers and Knoop indenter under loads of $1.96 \mathrm{~N}$. The load was maintained for $15 \mathrm{~s}$ holding time. The $H_{\mathrm{V}}$ and $H_{\mathrm{K}}$ values were calculated using following equations $[24,25]$ :

$$
\begin{aligned}
& H_{\mathrm{V}}=\frac{(1.8544) P}{d^{2}} \\
& H_{\mathrm{K}}=\frac{(14.299) P}{d^{2}}
\end{aligned}
$$

where $P=$ load $(\mathrm{N})$ and $d=$ half-length of long diagonal $(\mu \mathrm{m})$. The $E$ and $K_{\text {IC }}$ values were also calculated using the following equations: $[24,26]$

$$
\begin{aligned}
E & =\frac{\alpha H_{\mathrm{K}}}{(b / a)-\left(b^{\prime} / a^{\prime}\right)} \\
K_{\mathrm{IC}} & =0.016\left(\frac{E}{H_{\mathrm{V}}}\right)^{1 / 2}\left(\frac{P}{c^{3 / 2}}\right)
\end{aligned}
$$

where $\alpha=$ Marshall constant ( $\sim 0.45), b / a=$ length of the $H_{\mathrm{K}}$ tip mark with short diagonal/length of the $H_{\mathrm{K}}$ tip mark with long diagonal (0.14), $b^{\prime} / a^{\prime}=$ length of the $H_{\mathrm{K}}$ indentation with short diagonal/length of the $H_{\mathrm{K}}$ indentation with long diagonal, and $c=$ crack length (m). All mechanical corresponding values are also displayed in Table 2 . Based on Fig. 4 and Table 2, it can be seen that the $H_{\mathrm{V}}$ and $H_{\mathrm{K}}$ values of the unmodified sample were $5.30 \mathrm{GPa}$ and $4.10 \mathrm{GPa}$, respectively. The $H_{\mathrm{V}}$ and $H_{\mathrm{K}}$ values initially increased with increasing the additive content, and then reached the maximum value of $6.30 \mathrm{GPa}$ and $5.10 \mathrm{GPa}$, respectively, for the $x=0.03$ ceramic. An improvement of mechanical properties in the ceramics with high additive concentration is likely due to the effect of the reduced average grain size and densification improvement [27]. From $E$ and $K_{\text {IC }}$ studied in Fig. 4(b), it was found that $E$ and $K_{\mathrm{IC}}$ increased with the increasing of the additive content. The maximum $E=97 \mathrm{GPa}$ and $K_{\mathrm{IC}}=$ $1.95 \mathrm{MPa} . \mathrm{m}^{1 / 2}$ were also obtained for the $x=0.03$ ceramic. Based on the multi-domain grain model, ceramics with smaller grain size could possess single domain state and residual stress generated during sintering could not be released; this may lead to the improvement of the apparent $K_{\text {IC }}$ [21]. Moreover, the additive caused fracture behavior to switch from intergranular to transgranular mode, suggesting an increase in grain boundary strength. This may be another reason for $K_{\mathrm{IC}}$ improvement. Hence, it seems that the maximum mechanical properties obtained in this study could be correlated to the
Table 3 Electrical and magnetic properties of the $(1-x)$ (BNKT-BST)- $x$ BFTa ceramics.

\begin{tabular}{lccccc}
\hline$x$ & $\varepsilon_{r}^{\dagger}$ & $\tan \delta^{\dagger}$ & $\begin{array}{c}J \\
\left(\mathrm{~A} / \mathrm{cm}^{2}\right)\end{array}$ & $\begin{array}{c}\rho \\
\left(10^{11} \Omega \mathrm{m}\right)\end{array}$ & $\begin{array}{c}-M C \\
(\%)\end{array}$ \\
\hline 0 & 1616 & 0.051 & $5.74 \times 10^{-6}$ & 5.23 & 0.09 \\
0.01 & 1712 & 0.056 & $5.86 \times 10^{-6}$ & 5.12 & 2.10 \\
0.02 & 1746 & 0.060 & $6.09 \times 10^{-6}$ & 4.93 & 2.11 \\
0.03 & 1799 & 0.064 & $9.80 \times 10^{-6}$ & 3.06 & 2.19 \\
\hline
\end{tabular}

${ }^{\dagger}$ Dielectric data obtained at room temperature and a frequency of $1 \mathrm{kHz}$.
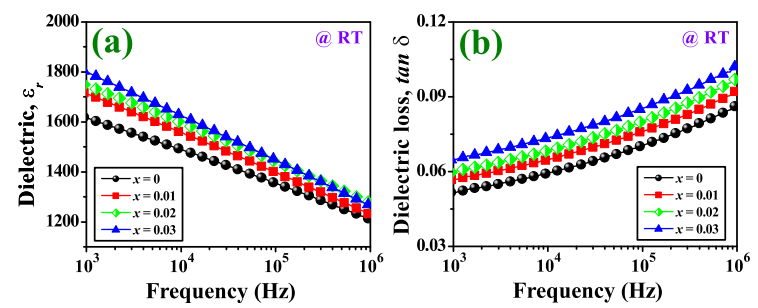

Fig. 5 (a) Dielectric constant $\left(\varepsilon_{r}\right)$ and (b) dielectric loss $(\tan \delta)$ as a function of frequency of the $(1-x)$ (BNKTBST)- $x$ BFTa ceramics measured at room temperature.

combination of smaller grain size, densification improvement and optimum strength of grains and grain boundaries [23].

At room temperature, dielectric constant $\left(\varepsilon_{r}\right)$ and dielectric loss $\tan \delta$ as a function of frequency for all ceramics are shown in Fig. 5. The $\varepsilon_{r}$ decreased with increasing the measurement frequencies whereas $\tan \delta$ values increased. The $\varepsilon_{r}$ and $\tan \delta$ measured at a frequency of $1 \mathrm{kHz}$ are also listed in Table 3. It can be seen that the dielectric constant was improved by the additive. The $\varepsilon_{r}$ (at $1 \mathrm{kHz}$ and RT) increased from 1616 for the unmodified ceramic to 1799 for the $x=0.03$ ceramic while the dielectric loss was slightly increased with the additive. In this work, the better densification of the modified ceramics may be a factor for the improvement of dielectric properties [28]. However, the slight increase in dielectric loss for the samples contained higher amount of the additive may be related to a formation of $\mathrm{Fe}^{2+}$ and $\mathrm{Fe}^{3+}$ in the samples [29]. This may produce an enhancement of electrical conduction due to electron hoping mechanism between $\mathrm{Fe}^{2+}$ and $\mathrm{Fe}^{3+}$.

In this work, the effect of an applied magnetic field on dielectric constant at room temperature $\left(\varepsilon_{r}\right)$ was also studied. A change in the $\varepsilon_{r}$ value under the applied magnetic field $(H)$ was observed. The magnetocapacitance $(-M C \%)$ was calculated via the 


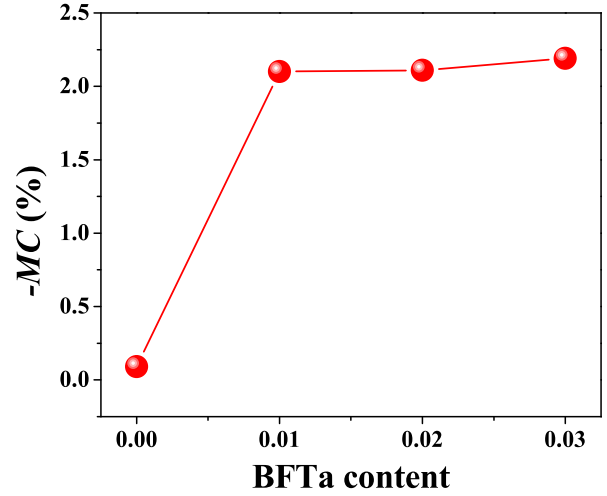

Fig. 6 Plot of the magnetocapacitance $(-M C)$ value as a function of BFTa content of the ceramics.

following equation: $[9,30,31]$

$$
-M C(\%)=\frac{\varepsilon(H)-\varepsilon(0)}{\varepsilon(0)} \times 100
$$

where $\varepsilon(H)$ is the dielectric constant under an applied magnetic field of 1 Tesla and $1 \mathrm{kHz}$ (at RT) and $\varepsilon(0)$ is the dielectric constant without an applied magnetic field. Based on Fig. 6 and Table 3, the $-M C \%$ value sharply increased from $0.09 \%$ for the unmodified sample to $2.10 \%$ for the $x=0.01$ ceramic, but subsequently slightly increased with further increasing the additive content. The maximum value of $-M C \%$ is $2.19 \%$ for the $x=0.03$ ceramic at the maximum magnetic field 1 Tesla and a frequency of $1 \mathrm{kHz}$, suggesting that the additive produced the MC effect [9]. This may be due to the change in resistance at bulk grain and grain boundary of the samples after the additive was added. These resistances can be changed under the applied magnetic field $[9,32]$, as a result in a change of $\varepsilon_{r}$ value [33].

Leakage current density $(J)$ versus applied electric field $(E)$ of the ceramics was carried out as seen in Fig. 7 and the values are listed in Table 3. The unmodified ceramic showed $J$ value of approximately $5.74 \times 10^{-6} \mathrm{~A} / \mathrm{cm}^{2}$. An increase in the leakage current was observed for the higher additive content ceramics. The $J$ value increased with increasing amount of the additive at high electric fields $(30 \mathrm{kV} / \mathrm{cm})$, and exhibited the maximum value of $9.80 \times 10^{-6} \mathrm{~A} / \mathrm{cm}^{2}$ for the the $x=0.03$ ceramic. The presence of leaky behaviour for the modified ceramic is probably because the additive produced higher leakage currents which can be linked with the electron hoping mechanism. The higher additive content ceramics exhibited the higher conductivity

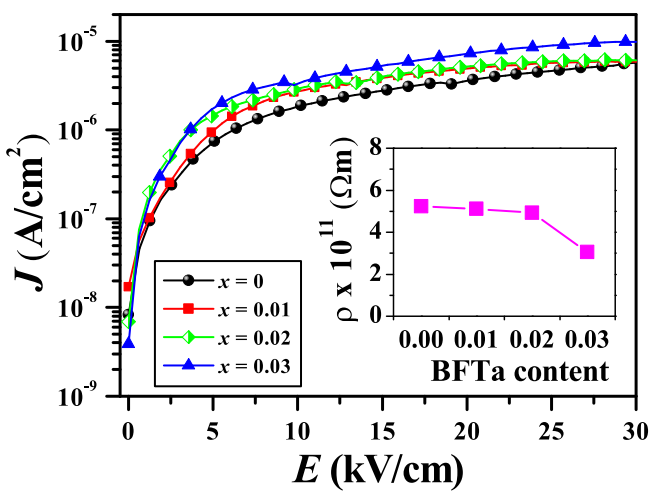

Fig. 7 Leakage current density $(J)$ versus applied electric field $(E)$ of the $(1-x)$ (BNKT-BST)- $x$ BFTa ceramics (inset: resistivity as a function of BFTa content at $30 \mathrm{kV} / \mathrm{cm}$ ).

and were easy to breakdown when applied voltages. As expected, the resistivity (at $30 \mathrm{kV} / \mathrm{cm}$ ) was also found to decrease with the amount of the additive as seen in the inset of Fig. 7. This is in accordance with the result of dielectric loss value.

\section{CONCLUSION}

In this work, the (1-x)(BNKT-BST)- $x$ BFTa ceramics have been successfully synthesized by a solid-state mixed oxide method. The coexistence of rhombohedral and tetragonal phases is present throughout the entire compositional range. The reduction of grain size was observed when the additive was added. The addition of BFTa was also found to improve the densification, mechanical and dielectric properties of the BNKT-BST ceramics. The $x=0.03$ ceramic showed the maximum room temperature dielectric properties $\left(\varepsilon_{r}=1799, \tan \delta=0.064\right)$ and mechanical properties $\left(H_{\mathrm{V}}=6.30 \mathrm{GPa}, H_{\mathrm{K}}=5.30 \mathrm{GPa}\right.$, $E=97 \mathrm{GPa}$, and $K_{\mathrm{IC}}=1.95 \mathrm{MPa}^{1 / 2}$ ) compared to those of the end-members. The leakage current density $(J)$ and magnetocapacitance $(-M C \%)$ values increased while the resistivity $(\rho)$ was found to decrease with the amount of the additive. From the results, the BFTa additive can improve both mechanical and electrical properties of the studied ceramics. Overall, these results indicate that these ceramics are one of the promising candidates for further development for electrical applications.

Acknowledgements: This research work was supported by the Thailand Research Fund (TRF, BRG6080002), National Research Council of Thailand and partially supported by Chiang Mai University, Materials Science Research Center, Research Center in Physics and Astronomy, Faculty of Science, Chiang Mai University. Department of 
Physics and Materials Science, Faculty of Science, Chiang Mai University. Technology Research Institute, Chiang Mai University is also acknowledged.

\section{REFERENCES}

1. Verma A, Yadav AK, Kumar S, Srihari V, Jangir R, Poswal HK, Biring S, Sen S (2019) Enhanced energy storage properties in A-site substituted $\mathrm{Na}_{0.5} \mathrm{Bi}_{0.5} \mathrm{TiO}_{3}$ ceramics. $J$ Alloys Compd 792, 95-107.

2. Dong G, Fan H, Shi J, Li Q (2018) Large strain response with low driving field in $\mathrm{Bi}_{1 / 2} \mathrm{Na}_{1 / 2} \mathrm{TiO}_{3}$ $\mathrm{Bi}_{1 / 2} \mathrm{~K}_{1 / 2} \mathrm{TiO}_{3}-\mathrm{Bi}\left(\mathrm{Mg}_{2 / 3} \mathrm{Nb}_{1 / 3}\right) \mathrm{O}_{3}$ ceramics. J Am Ceram Soc 101, 3947-3955.

3. Wu L, Shen B, Hu Q, Chen J, Wang Y, Xia Y, Yin J, Liu Z (2017) Giant electromechanical strain response in lead-free $\mathrm{SrTiO}_{3}$-doped $\left(\mathrm{Bi}_{0.5} \mathrm{Na}_{0.5} \mathrm{TiO}_{3}-\mathrm{BaTiO}_{3}\right)$ $\mathrm{LiNbO}_{3}$ piezoelectric ceramics. J Am Ceram Soc 100, 4670-4679.

4. Butnoi P, Manotham S, Jaita P, Randorn C, Rujijanagul G (2018) High thermal stability of energy storage density and large strain improvement of lead-free $\mathrm{Bi}_{0.5}\left(\mathrm{Na}_{0.40} \mathrm{~K}_{0.10}\right) \mathrm{TiO}_{3}$ piezoelectric ceramics doped with La and Zr. J Eur Ceram Soc 38, 3822-3832.

5. Manotham S, Butnoi P, Jaita P, Kumar N, Chokethawai K, Rujijanagul G, Cann DP (2018) Large electric field-induced strain and large improvement in energy density of bismuth sodium potassium titanate-based piezoelectric ceramics. J Alloys Compd 739, 457-467.

6. Jaita P, Butnoi P, Sanjoom R, Randorn C, Yimnirun R, Rujijanagul G (2017) Electric field-induced strain response of lead-free $\mathrm{Fe}_{2} \mathrm{O}_{3}$ nanoparticles modified $\mathrm{Bi}_{0.5}\left(\mathrm{Na}_{0.80} \mathrm{~K}_{0.20}\right)_{0.5} \mathrm{TiO}_{3}-0.03\left(\mathrm{Ba}_{0.70} \mathrm{Sr}_{0.30}\right) \mathrm{TiO}_{3}$ piezoelectric ceramics. Ceram Int 43, S2-S9.

7. Ullah A, Malik RA, Ullah A, Lee DS, Jeong SJ, Lee JS, Kim IW, Ahn CW (2014) Electric-field-induced phase transition and large strain in lead-free $\mathrm{Nb}$-doped BNKT-BST ceramics. J Eur Ceram Soc 34, 29-35.

8. Ullah A, Ullah A, Kim IW, Lee DS, Jeong SJ, Ahn CW (2014) Large electromechanical response in leadfree La-doped BNKT-BST piezoelectric ceramics. J Am Ceram Soc 97, 2471-2478.

9. Manotham S, Butnoi P, Jaita P, Pinitsoontorn S, Sweatman D, Eitssayeam S, Pengpat K, Rujijanagul $G$ (2016) Dielectric and magnetic properties of $\mathrm{Ba}\left(\mathrm{Fe}_{1 / 2} \mathrm{Ta}_{1 / 2}\right) \mathrm{O}_{3}-\mathrm{BiFeO}_{3}$ ceramics. $J$ Electron Mater 45, 5948-5955.

10. Wang Z, Chen XM, Ni L, Liu Y, Liu XQ (2007) Dielectric relaxations in $\mathrm{Ba}\left(\mathrm{Fe}_{1 / 2} \mathrm{Ta}_{1 / 2}\right) \mathrm{O}_{3}$ giant dielectric constant ceramics. Appl Phys Lett 90, ID 102905.

11. Dutta A, Sinha TP (2011) Structural and dielectric properties of $\mathrm{A}\left(\mathrm{Fe}_{1 / 2} \mathrm{Ta}_{1 / 2}\right) \mathrm{O}_{3}[\mathrm{~A}=\mathrm{Ba}, \mathrm{Sr}, \mathrm{Ca}]$. Mater Res Bull 46, 518-524.

12. Phatungthane T, Rujijanagul G, Pengpat K, Eitssayeam S, Tunkasiri T, Cotica LF, Guo R, Bhalla A (2014) Dielectric and impedance measurements on $\quad(1-x) \mathrm{Ba}\left(\mathrm{Fe}_{1 / 2} \mathrm{Ta}_{1 / 2}\right) \mathrm{O}_{3}-x \mathrm{Ba}\left(\mathrm{Zn}_{1 / 3} \mathrm{Ta}_{2 / 3}\right) \mathrm{O}_{3}$ ceramics. Curr Appl Phys 14, 1819-1824.

13. Dua J, An F, Xu Z, Cheng R, Chu R, Yi X, Hao J, Li W (2016) Effects of $\mathrm{BiFe}_{0.5} \mathrm{Ta}_{0.5} \mathrm{O}_{3}$ addition on electrical properties of $\mathrm{K}_{0.5} \mathrm{Na}_{0.5} \mathrm{NbO}_{3}$ lead-free piezoelectric ceramics. Ceram Int 42, 1943-1949.

14. Li G, Liu S, Liao F, Tian S, Jing X, Lin J, Uesu Y, Kohn $\mathrm{K}$, et al (2004) The structural and electric properties of the perovskite system $\mathrm{BaTiO}_{3}-\mathrm{Ba}\left(\mathrm{Fe}_{1 / 2} \mathrm{Ta}_{1 / 2}\right) \mathrm{O}_{3}$. $J$ Solid State Chem 177, 1695-1703.

15. Marshall DB, Noma T, Evans AG (1982) A simple method for determining elastic modulus to hardness ratios using Knoop indentation measurements. $J$ Am Ceram Soc 65, 175-176.

16. Antis GR, Chantikul P, Lawn BR, Marshall DB (1981) A critical evaluation of indentation techniques for measuring fracture toughness: I, direct crack measurement. $J$ Am Ceram Soc 64, 533-538.

17. Ullah A, Ahn CW, Hussain A, Lee SY, Lee HJ, Kim IW (2010) Phase transitions and large electric fieldinduced strain in $\mathrm{BiAlO}_{3}$-modified $\mathrm{Bi}_{0.5}(\mathrm{NaK})_{0.5} \mathrm{TiO}_{3}$ lead-free piezoelectric ceramics. Cur Appl Phys 10, 1174-1181.

18. Malik RA, Hussain A, Zaman A, Maqbool A, Rahman JU, Song TK, Kim WJ, Kim MH (2015) Structureproperty relationship in lead-free $\mathrm{A}$ - and $\mathrm{B}$-site co-doped $\mathrm{Bi}_{0.5}\left(\mathrm{Na}_{0.84} \mathrm{~K}_{0.16}\right)_{0.5} \mathrm{TiO}_{3}-\mathrm{SrTiO}_{3}$ incipient piezoceramics. RSC Adv 5, 96953-96964.

19. Aksel E, Forrester JS, Kowalski B, Deluca M, Damjanovic D, Jones JL (2012) Structure and properties of Fe-modified $\mathrm{Na}_{0.5} \mathrm{Bi}_{0.5} \mathrm{TiO}_{3}$ at ambient and elevated temperature. Phys Rev B 85, ID 024121.

20. Bai W, Liu F, Li P, Shen B, Zhai J, Chen H (2015) Structure and electromechanical properties in $\mathrm{Bi}_{0.5} \mathrm{Na}_{0.5} \mathrm{TiO}_{3}$-based lead-free piezoceramics with calculated end-member $\mathrm{Bi}\left(\mathrm{Ni}_{0.5} \mathrm{Ti}_{0.5}\right) \mathrm{O}_{3}$. J Eur Ceram Soc 35, 3457-3466.

21. Chiang YM, Birnie III DP, Kingery WD (1997) Physical Ceramics, John Wiley \& Sons Inc, New York.

22. Ramana EV, Figueiras F, Mahajan A, Tobaldi DM, Costa BFO, Graça MPF, Valente MA (2016) Effect of Fe-doping on the structure and magnetoelectric properties of $\left(\mathrm{Ba}_{0.85} \mathrm{Ca}_{0.15}\right)\left(\mathrm{Ti}_{0.9} \mathrm{Zr}_{0.1}\right) \mathrm{O}_{3}$ synthesized by a chemical route. $J$ Mater Chem C 4, 1066-1079.

23. Jaita P, Watcharapasorn A, Jiansirisomboon S (2010) A role of BNLT compound addition on structure and properties of PZT ceramics. Solid State Sci 12, 1608-1614.

24. Strecker K, Ribeiro S, Hoffmann M, Hoffmann J (2005) Fracture toughness measurements of LPSSiC: a comparison of the indentation technique and the SEVNB method. Mat Res 8, 201-205.

25. Morrell R (1990) Guidelines for conducting hardness tests on advanced ceramics materials. VAMAS Technical Report 8, National Physical Laboratory, Teddington.

26. Domingues NB, Galvão BR, Ribeiro S, Junior AAA, 
Longhini D, Adabo GL (2016) Comparison of the indentation strength and single-edge-v-notched beam methods for dental ceramic fracture toughness testing. Braz J Oral Sci 15, 109-112.

27. Kruea-In C, Inthong S, Leenakul W (2017) Effects of $\mathrm{NiO}$ nanoparticles on physical and mechanical properties of BNKT lead-free ceramics. Appl Mech Mater 866, 282-286.

28. Jaita P, Manotham S, Butnoi P, Sanjoom R, Arkornsakul P, Sweatman DR, Kruea-In C, Tunkasiri T (2018) Themechanical and electrical properties of modified-BNKT lead-free ceramics. Int Ferroelectrics 187, 147-155.

29. Wang $Z$, Chen XM, Liu XQ (2009) $\mathrm{Ba}\left[\left(\mathrm{Fe}_{0.9} \mathrm{Al}_{0.1}\right)_{0.5} \mathrm{Ta}_{0.5}\right] \mathrm{O}_{3}$ ceramics with extended giant dielectric constant step and reduced dielectric loss. J Appl Phys 105, ID 034114.
30. Pattanayak R, Raut S, Kuila S, Chandrasekhar M, Panigrahi S (2017) Multiferroism of $\left[\mathrm{Na}_{0.5} \mathrm{Bi}_{0.5} \mathrm{TiO}_{3}\right.$ $\mathrm{BaFe}_{12} \mathrm{O}_{19}$ ] lead-free novel composite systems. Mater Lett 209, 280-283.

31. Mane SM, Tirmali PM, Ranjit B, Khan M, Khan N, Tarale AN, Kulkarni SB (2018) Studies on magnetocapacitance, dielectric, ferroelectric, and magnetic properties of microwave sintered $(1-x)\left(\mathrm{Ba}_{0.8} \mathrm{Sr}_{0.2} \mathrm{TiO}_{3}\right)-x\left(\mathrm{Co}_{0.9} \mathrm{Ni}_{0.1} \mathrm{Fe}_{2} \mathrm{O}_{4}\right)$ multiferroic composite. Solid State Sci 81, 43-50.

32. Catalan G (2006) Magnetocapacitance without magnetoelectric coupling. Appl Phys Lett 88, ID 102902.

33. Sanjoom K, Pengpat K, Eitssayeam S, Tunkasiri T, Rujijanagul G (2014) Dielectric properties of $\mathrm{Ga}_{2} \mathrm{O}_{3}$ dopedbarium iron niobate ceramics. Phys Status Solidi A 211, 1720-1725. 